\title{
Modelling of corrosion-induced cover cracking in reinforced concrete by an embedded cohesive crack finite element
}

\author{
Santiago Guzmán a , Jaime C. Gálvez ${ }^{\text {a,* }}$, José M. Sancho ${ }^{\mathrm{b}}$
}

\begin{abstract}
A B S T R A C T
Corrosion of a reinforcement bar leads to expansive pressure on the surrounding concrete that provokes internal cracking and, eventually, spalling and delamination. Here, an embedded cohesive crack 2D finite element is applied for simulating the cracking process. In addition, four simplified analytical models are introduced for comparative purposes.

Under some assumptions about rust properties, corrosion rate, and particularly, the accommodation of oxide products within the open cracks generated in the process, the proposed FE model is able to estimate time to surface cracking quite accurately. Moreover, emerging cracking patterns are in reasonably good agreement with expectations.

As a practical case, a prototype application of the model to an actual bridge deck is reported.
\end{abstract}

\section{Introduction}

In reinforced concrete ( $\mathrm{RC}$ ) structures, the alkaline environment of concrete ( $\mathrm{pH}$ of 12-13) implies a passive film around the reinforcement bars that provides steel with corrosion protection. However, phenomena such as carbonatation or chloride attack may lead this film to be destroyed, once the $\mathrm{pH}$ drops below nine or the chloride content in the re-bar surrounding exceeds a critical value. If sufficient moisture and oxygen are available, oxidation of steel begins and rust products are generated, which occupy much greater volume (about four-six times) than the original steel consumed. Subsequently, tensile forces are generated and concrete cover cracking (and eventually, spalling and delamination) appears much earlier than the point at which a significant reinforcement cross-section reduction takes place [1].

Historically, in addition to empirical approaches [17], analytical models based on the thick-walled cylinder approach have been widely used. In function of geometry, material properties and, especially, the constitutive equation for the non-linear behaviour of concrete after cracking, time to cover cracking once the corrosion process begins, is predicted. In spite of their simplicity and shortcomings [7], these models have been successfully adopted in previous works (e.g., [15,3,4,10]). For reference, certain analytical models will be presented here as well.

However, for a more comprehensive analysis of concrete cracking, the finite difference method [21] and, above all, the finite element method $[16,8,14,9]$ are applied. Two FE approaches are highlighted: smeared cracking and discrete cracking. The former described the cracked concrete as a fictitious continuum, while the latter considers cracks directly as geometric discontinuities. 


\section{Nomenclature}

$\boldsymbol{b}^{+} \quad$ sum of shape function gradient for nodes affected by displacement jump

$\boldsymbol{b}_{l}(\mathbf{x}) \quad$ shape function gradient for node I

c concrete cover

D diameter

$D_{2} \quad$ ideal combined diameter of reinforcement plus corrosion products, free expanded

$D_{i} \quad$ initial (nominal) diameter of the reinforcement bar

$D_{i^{*}} \quad$ diameter of the reinforcement bar reduced by corrosion process

$d_{c} \quad$ radial displacement at $r=R_{i}+d_{o}$

$d_{o} \quad$ so-called porous zone of finite thickness around the reinforcement bar

E tensor of elastic moduli

$E_{c} \quad$ concrete Young's modulus

$E_{c 1} \quad$ concrete Young's modulus in the cracked zone (after cracking)

$E_{c 2} \quad$ initial concrete Young's modulus (before cracking)

$E_{\text {ef }} \quad$ effective concrete Young's modulus

$E_{s} \quad$ steel Young's modulus

$F \quad$ Faraday constant

$f_{c} \quad$ compressive strength of concrete

$f_{c t} \quad$ concrete tensile capacity

$f(w) \quad$ classical softening function for mode I

$G_{F} \quad$ specific fracture energy

$H(\boldsymbol{x}) \quad$ heaviside jump function

$i_{\text {cor }}$ annual mean corrosion rate

$j_{s} \quad$ loss of steel mass

$k_{p} \quad$ rust production parameter

$M_{F E} \quad$ atomic weight of iron

$n$ ionic valence

n normal vector

$N_{l}(\boldsymbol{x}) \quad$ traditional shape function for node I

$p_{r} \quad$ uniform pressure on the re-bar

$r \quad$ radius

$R_{2} \quad$ ideal combined radius of reinforcement plus corrosion products, free expanded

$R_{c} \quad$ radius of the crack front at which the tensile capacity of the concrete is reached

$R_{i} \quad$ initial (nominal) radius of the reinforcement bar

$R_{i}^{*} \quad$ radius of the reinforcement bar reduced by corrosion process

$R_{o} \quad$ distance from re-bar centre to concrete surface

$s \quad$ re-bar spacing

$t$ time

$t$ traction vector

$u(r) \quad$ radial displacement at radius $r$

$u_{c} \quad$ radial displacement at radius $r=R_{c}$

$u_{s} \quad$ radial displacement at radius $r=R_{2}$

$\boldsymbol{u}^{I} \quad$ nodal displacement

$w \quad$ crack opening

$w \quad$ crack displacement vector

$w_{\text {th }} \quad$ crack opening threshold value for crack adaptability

$\tilde{w} \quad$ equivalent crack opening

$W_{r} \quad$ amount of rust products per unit length of the reinforcement generated by the corrosion process

$W_{s} \quad$ amount of steel per unit length of the reinforcement consumed by the corrosion process

$\Delta \quad$ re-bar radius increment due to free expansion of corrosion products

$\varepsilon^{a} \quad$ apparent strain tensor

$\varepsilon^{c} \quad$ continuous part of the strain tensor

$\mu_{\nu} \quad$ ratio of volume of expansive corrosion products to the volume of steel consumed

$\mu_{w} \quad$ ratio of molecular weight of iron to the molecular weight of the corrosion products

$v_{c} \quad$ concrete Poisson's ratio

$v_{c 1} \quad$ concrete Poisson's ratio in the cracked zone (after cracking)

$v_{c 2} \quad$ initial concrete Poisson's ratio (before cracking)

$v_{s} \quad$ steel Poisson's ratio

$\rho_{r} \quad$ rust density

$\rho_{s} \quad$ steel density 


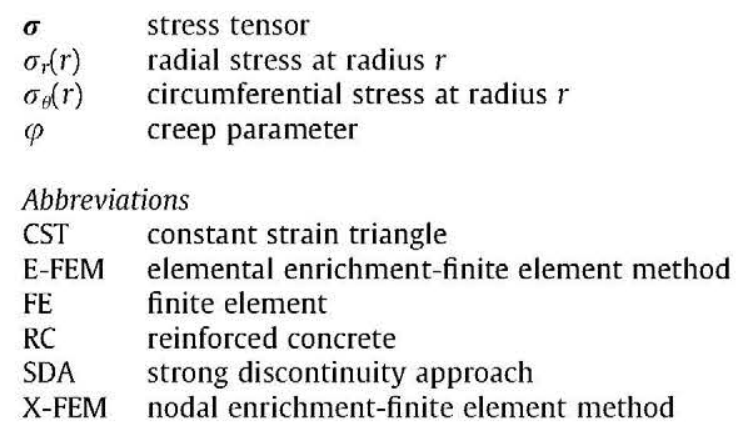

Both of them have been successfully complemented in the last years by the application of the so-called Strong Discontinuity Approach (SDA, [25]) by means of both elemental (E-FEM) or nodal (X-FEM) enrichments. These two methods provide the same qualitative and quantitative results for sufficiently refined meshes, with relative computational cost X-FEM/E-FEM growing linearly with the number of modelled cracks [20]. Based on the E-FEM approach, an embedded cohesive crack 2D finite element [22-24] is chosen here to analyse the concrete fracture process. In order to facilitate the localisation of the cracks, the geometric model avoids the classical central symmetry condition with respect to the bar axis and a contact algorithm is employed to reproduce the oxide-concrete interface.

In addition, the proposed procedure does not require "crack tracking" to avoid crack locking phenomena, as in the cases of most SDA practical implementations. No crack continuity is enforced or crack exclusion zone defined, but a certain amount of crack adaptability within each element is introduced. The model has been successful when applied to the fracture of concrete and only requires standard properties of the material, measured by standardised methods.

Due to the particularities of the adopted element, some theoretical aspects will be examined before the exposition of an application case based on some experimental data by Liu [13].

\section{Analytical models}

Most widely used analytical models for reproducing concrete cover cracking due to corrosion of the reinforcement bars are based on the thick-walled cylinder approach. According to Fig. 1, the internal circular boundary at the interface of the reinforcement and the concrete is displaced to accommodate the expansive corrosion products [2]. The initial radius of the reinforcement bar is $R_{i}$ and $c$ is the clear concrete cover to the reinforcement. $R_{c}$ represents the radius of the crack front at which the tensile capacity of the concrete is reached. Once $R_{c}$ becomes $R_{o}=R_{i}+c$; the concrete cover is assumed to be fully cracked.

Following Liu and Weyers [15], a so-called "porous" zone of finite thickness $d_{o}$ around the reinforcement bar is included to account for voids at the interface steel-concrete that allow a first diffusion of corrosion products with no contribution to the pressure exerted on the concrete.

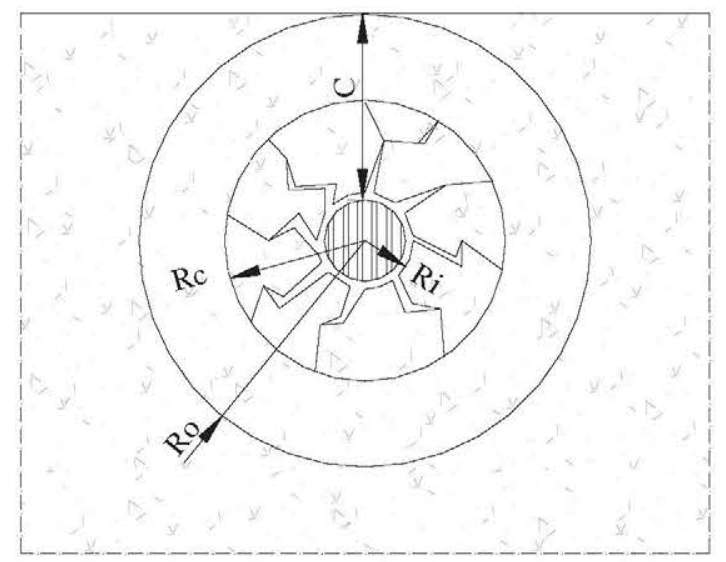

Fig. 1. Sketch of cover concrete cracking due to expansion of re-bar corrosion products. 
Basic assumptions are the following:

1. The corrosion process around the reinforcement bar is uniform and can be described through a radial displacement. An axi-symmetric condition is then considered.

2. For the sake of simplicity, a two-dimensional approach with isotropic materials is proposed. A plane strain formulation is employed to account for the bulk concrete of the structural element around the reinforcement bar.

3. Both the initiation and the rate (in terms of oxide production) of corrosion are known.

4. No other stresses apart from the expansion of corrosion products are considered.

5. No amount of the corrosion products accommodate within the open radial cracks.

Four analytical models are developed mainly in function of post-cracking behaviour of concrete. In spite of their simplicity and inconsistencies [7], they will be useful to delimitate times to cover cracking, as shown below. Appendix A provides detailed information for each model.

\subsection{Model 1: linear elastic concrete}

Only the concrete cylinder around the reinforcement bar is considered. The two basic parameters are $E_{c}$ (Young's modulus) and $v_{c}$ (Poisson's ratio). With respect to the elastic modulus, generally speaking, it refers to the effective modulus, i.e. considering a creep parameter $\varphi$, according to the expression:

$$
E_{e f}=\frac{E_{c}}{1+\varphi}
$$

This assumption is controversial when used in accelerated corrosion tests [7], though it is widely accepted in the literature for describing the elastic concrete behaviour in real long term situations.

Boundary conditions are given by the displacement $d_{c}$ in $r=R_{i}+d_{o}$ and null radial stress in $r=R_{o}$. The well-known elastic solution yields the relation:

$$
u(r)=\frac{A r}{2}+\frac{B}{r}
$$

where $u(r)$ means the radial displacement at any radius $r$. The constants $A$ and $B$ are given by:

$$
B=\frac{d_{c} R_{o}^{2}\left(R_{i}+d_{o}\right)}{\left[R_{0}^{2}+\left(1-2 v_{c}\right)\left(R_{i}+d_{o}\right)^{2}\right]}=\frac{A R_{0}^{2}}{2\left(1-2 v_{c}\right)}
$$

The corresponding radial and circumferential stresses arise immediately:

$$
\begin{aligned}
& \sigma_{r}(\boldsymbol{r})=\frac{E_{c}}{1+v_{c}}\left[\frac{A}{2\left(1-2 v_{c}\right)}-\frac{B}{r^{2}}\right] \\
& \sigma_{\theta}(\boldsymbol{r})=\frac{E_{c}}{1+v_{c}}\left[\frac{A}{2\left(1-2 v_{c}\right)}+\frac{B}{r^{2}}\right]
\end{aligned}
$$

It should be noted that this is only a theoretical model with the purpose to give results for reference. Since steel is not explicitly considered, the radius increment $\Delta$ of the reinforcement bar equals to the sum of $d_{c}+d_{o}$.

In the inner border of the concrete block:

$$
\sigma_{r}\left(R_{i}+d_{0}\right)=-p_{r}=\frac{-E_{c} d_{c}\left(R_{0}^{2}-\left(R_{i}+d_{o}\right)^{2}\right)}{\left(1+v_{c}\right)\left(R_{o}^{2}+\left(1-2 v_{c}\right)\left(R_{i}+d_{o}\right)^{2}\right)\left(R_{i}+d_{0}\right)}
$$

Finally, the radius of the crack front $R_{c}$ at which the tensile capacity $f_{c t}$ of the concrete is reached, is obtained as follows:

$$
R_{c}=\sqrt{\frac{p_{r}\left(R_{i}+d_{o}\right)^{2} R_{o}^{2}}{f_{c t}\left(R_{o}^{2}-\left(R_{i}+d_{o}\right)^{2}\right)-p_{r}\left(R_{i}+d_{o}\right)^{2}}}
$$

The same equation is obtained by Bhargava et al. [3], but through the plane stress hypothesis.

\subsection{Model 2: linear elastic concrete and steel}

Steel and corrosion products are introduced as an only linear and elastic material defined by the parameters $E_{s}$ and $v_{s}$. The same boundary conditions as the previous model are involved in the concrete block and, regarding steel, $\sigma_{r}=-p_{r}$ (uniform) 


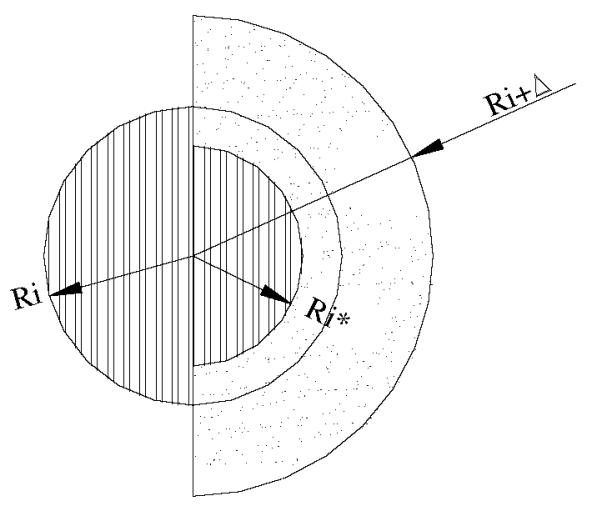

Fig. 2. Sketch of the corrosion process in the reinforcement bar.

and $u_{s}=-R_{2}+R_{i}+d_{o}+d_{c}$ in $r=R_{2}$; where $R_{2}$ represents the ideal combined radius of reinforcement plus corrosion products, i.e. the combined radius that would be reached if no restriction by the surround concrete were considered (see Fig. 2).

The bar is subjected to a uniform pressure. Then:

$$
\sigma_{s}=\frac{C E_{s}}{2\left(1+v_{s}\right)\left(1-2 v_{s}\right)}=-p_{r}
$$

where $C$ is evaluated immediately through $p_{r}$ value. This time, the radius increment $\Delta$ of the reinforcement bar equals the sum of $d_{c}+d_{0}-u_{s}$, with $u_{s}=C R_{2} / 2$ and $R_{2}=R_{i}+\Delta$. The following expression arises:

$$
d_{c}=\frac{R_{2}-\left(R_{i}+d_{o}\right)}{1+\frac{E_{c} R_{2}\left(1-2 v_{s}\right)\left(1+v_{s}\right)\left[R_{0}^{2}-\left(R_{i}+d_{0}\right)^{2}\right]}{E_{s}\left(1+v_{c}\right)\left(R_{i}+d_{o}\right)\left[R_{0}^{2}+\left(1-2 v_{c}\right)\left(R_{i}+d_{0}\right)^{2}\right]}}
$$

\subsection{Model 3: cracked concrete with no residual strength and linear elastic steel}

The linear elastic behaviour of concrete is limited up to the tensile strength $f_{c t}$. After cracking, the residual strength of concrete is considered null. New boundary condition appear, $\sigma_{\theta}=f_{c t}$ in $r=R_{c}$ while $\sigma_{r}=0$ in $r=R_{o}$ is maintained. Due to the fact that $R_{c}$ is unknown, an additional equation is required and obtained through the conservation of volume (equivalent to adopt a Poisson's ratio which tends to 0.5$): u_{c} R_{c}=d_{c}\left(R_{i}+d_{o}\right)$, where $u_{c}=u_{r}\left(R_{c}\right)$. Therefore:

$$
d_{c}=\frac{R_{2}-\left(R_{i}+d_{0}\right)}{1+\frac{E_{c} R_{2}\left(1-2 v_{s}\right)\left(1+v_{s}\right)}{E_{s} R_{c}^{2}} \frac{\left(R_{0}^{2}-R_{c}^{2}\right)\left(R_{i}+d_{0}\right)}{\left(1+v_{c}\right)\left(R_{0}^{2}+R_{c}^{2}\left(1-2 v_{c}\right)\right)}}
$$

\subsection{Model 4: cracked concrete with residual strength and linear elastic steel}

This model is similar to the previous one, though it takes into account some residual strength of concrete once cracking appears. A process of tension softening is considered. The elastic modulus for concrete in zone 2 (without cracking) is maintained equal to the original one, i.e. $E_{c 2}=E_{c}$; whereas, for the zone 1 (cracked zone), the secant slope of the descending branch of the stress-strain curve defines the value of $E_{c 1}$.

Relation between $d_{c}$ and $u_{c}$ is as follows:

$$
d_{c}=\frac{u_{c}\left[R_{c}^{2}+\left(R_{i}+d_{0}\right)^{2}\left(1-2 v_{c 1}\right)\right]}{2 R_{c}\left(R_{i}+d_{0}\right)\left(1-v_{c 1}\right)}-\frac{u_{c}\left(1+v_{c 1}\right)\left(1-2 v_{c 1}\right)\left(R_{0}^{2}-R_{c}^{2}\right)\left[\left(R_{i}+d_{0}\right)^{2}-R_{c}^{2}\right] E_{c 2}}{2 R_{c}\left(R_{i}+d_{0}\right)\left[R_{0}^{2}+R_{c}^{2}\left(1-2 v_{c 2}\right)\right]\left(1+v_{c 2}\right)\left(1-v_{c 1}\right) E_{c 1}}
$$

where

$$
u_{c}=\frac{R_{c}\left(1+v_{c 2}\right)\left[R_{c}^{2}\left(1-2 v_{c 2}\right)+R_{0}^{2}\right] f_{c t}}{\left(R_{0}^{2}+R_{c}^{2}\right) E_{c 2}}
$$


Generally speaking, iteration procedures are required to solve the problem. A finite difference method is proposed by Pantazopoulou and Papoulia [21] who also take into account the anisotropy of cracked concrete. In fact, a significant shortcoming of the description above is treating cracked concrete as an isotropic material. However, the four analytical models presented here aim only to obtain a first approach to the problem, based on their simplicity. A thorough and consistent analysis is to be developed through a finite element with cohesive embedded crack, as described hereafter.

\section{Finite element with cohesive embedded crack}

Numerical implementation of cohesive crack model used in the present paper was performed by Sancho et al. [23]. Some basics of the finite element formulation are extracted next, with special emphasis given to crack angle orientation and adaptability.

Consider an arbitrary 2D finite element, with a straight crack inside. The element is split into two sub-domains $A^{+}$and $A^{-}$, separated by a displacement jump w, as shown in Fig. 3, where a CST triangle is introduced.

According to the strong discontinuity approach (e.g. [19]), the approximated displacement field within the element can be written as:

$$
\boldsymbol{u}(\boldsymbol{x})=\sum_{(A)} N_{I}(\boldsymbol{x}) \boldsymbol{u}^{I}+\left[H(x)-N^{+}(\boldsymbol{x})\right] \boldsymbol{w}
$$

where $N_{f}(\boldsymbol{x})$ is the traditional shape function for node $I, \boldsymbol{u}^{I}$ the corresponding nodal displacement and $H(\boldsymbol{x})$ the Heaviside jump function across the crack plane. Moreover:

$$
N^{+}(\boldsymbol{x})=\sum_{\left(I \in A^{+}\right)} N_{l}(x)
$$

The strain tensor is obtained from the displacement field as a continuous part plus a Dirac's $\delta$ function on the crack line. The continuous part is given by:

$$
\boldsymbol{\varepsilon}^{c}(\boldsymbol{x})=\boldsymbol{\varepsilon}^{a}(\boldsymbol{x})-\left[\boldsymbol{b}^{+}(\boldsymbol{x}) \otimes \boldsymbol{w}\right]^{S}
$$

where $\varepsilon^{a}$ (the apparent strain tensor) and $\boldsymbol{b}^{+}$are obtained as follows:

$$
\begin{aligned}
\varepsilon^{a}(\boldsymbol{x}) & =\sum_{(A)}\left[\boldsymbol{b}_{I}(\boldsymbol{x}) \otimes \boldsymbol{u}^{I}\right]^{S} \\
\boldsymbol{b}^{+}(\boldsymbol{x}) & =\sum_{\left(A^{+}\right)} \boldsymbol{b}_{l}(\boldsymbol{x})
\end{aligned}
$$

with $\boldsymbol{b}_{f}(\boldsymbol{x})=\operatorname{grad} N_{f}(\boldsymbol{x})$ and superscript ${ }^{\mathrm{S}}$ indicating symmetric part of a tensor.

Regarding cohesive cracking, a simple generalisation of the cohesive crack to mixed mode is used which assumes that the traction vector $\boldsymbol{t}$ transmitted across the crack faces is parallel to the crack displacement vector $\boldsymbol{w}$ (central forces model). To address the possibility of unloading $[22,23]$ :

$$
\boldsymbol{t}=\frac{f(\tilde{w})}{\tilde{w}} \boldsymbol{w}
$$

where $f(\tilde{w})$ is the classical softening function for pure opening mode (Fig. 4) and $\tilde{w}$ is an equivalent crack opening defined as the historical maximum of the magnitude of the crack displacement vector.

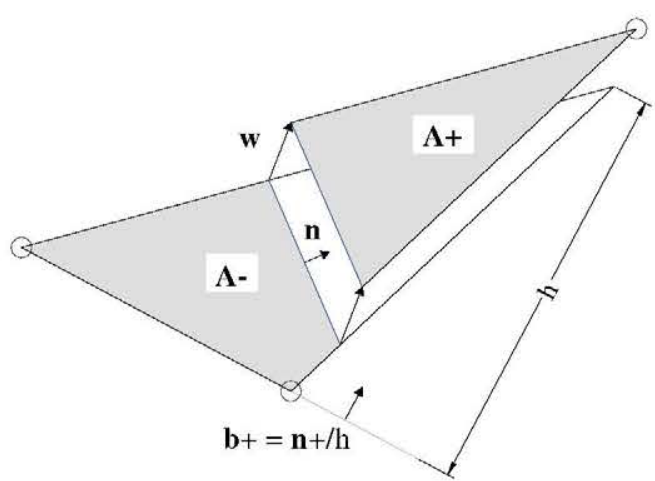

Fig. 3. CST element with an embedded crack. Geometric definitions. 


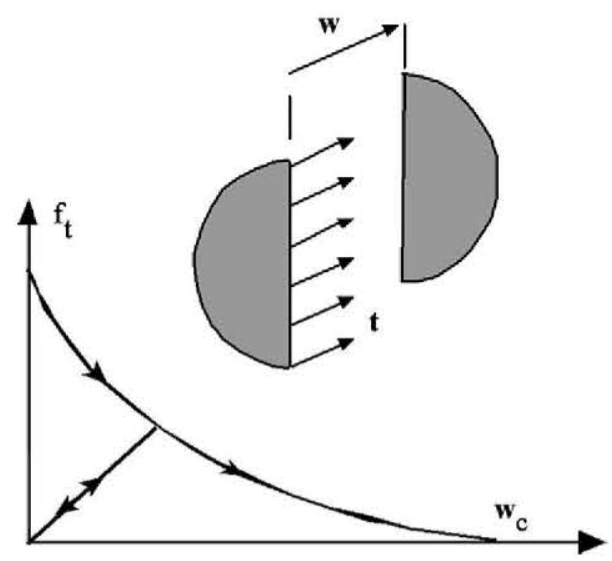

Fig. 4. Sketch of softening curve for the cohesive crack model.

Outside the crack line, an elastic and linear behaviour is assumed. The traction vector is given, from Eqs. (14) and (16), and local equilibrium $\boldsymbol{t}=\boldsymbol{\sigma} \cdot \boldsymbol{n}$ :

$$
\frac{f(\tilde{w})}{\tilde{w}} \boldsymbol{w}=\boldsymbol{E}:\left[\boldsymbol{\varepsilon}^{a}-\left(\boldsymbol{b}^{+} \otimes \boldsymbol{w}\right)^{S}\right] \cdot \boldsymbol{n}
$$

where $\mathbf{E}$ is the tensor of elastic moduli and $\boldsymbol{n}$ the normal vector to the crack.

Developing the former expression, finally:

$$
\left[\frac{f(\tilde{w})}{\tilde{W}} \mathbf{1}+\boldsymbol{n} \cdot \boldsymbol{E} \cdot \boldsymbol{b}^{+}\right] \cdot \boldsymbol{w}=\left[\boldsymbol{E}: \boldsymbol{\varepsilon}^{a}\right] \cdot \boldsymbol{n}
$$

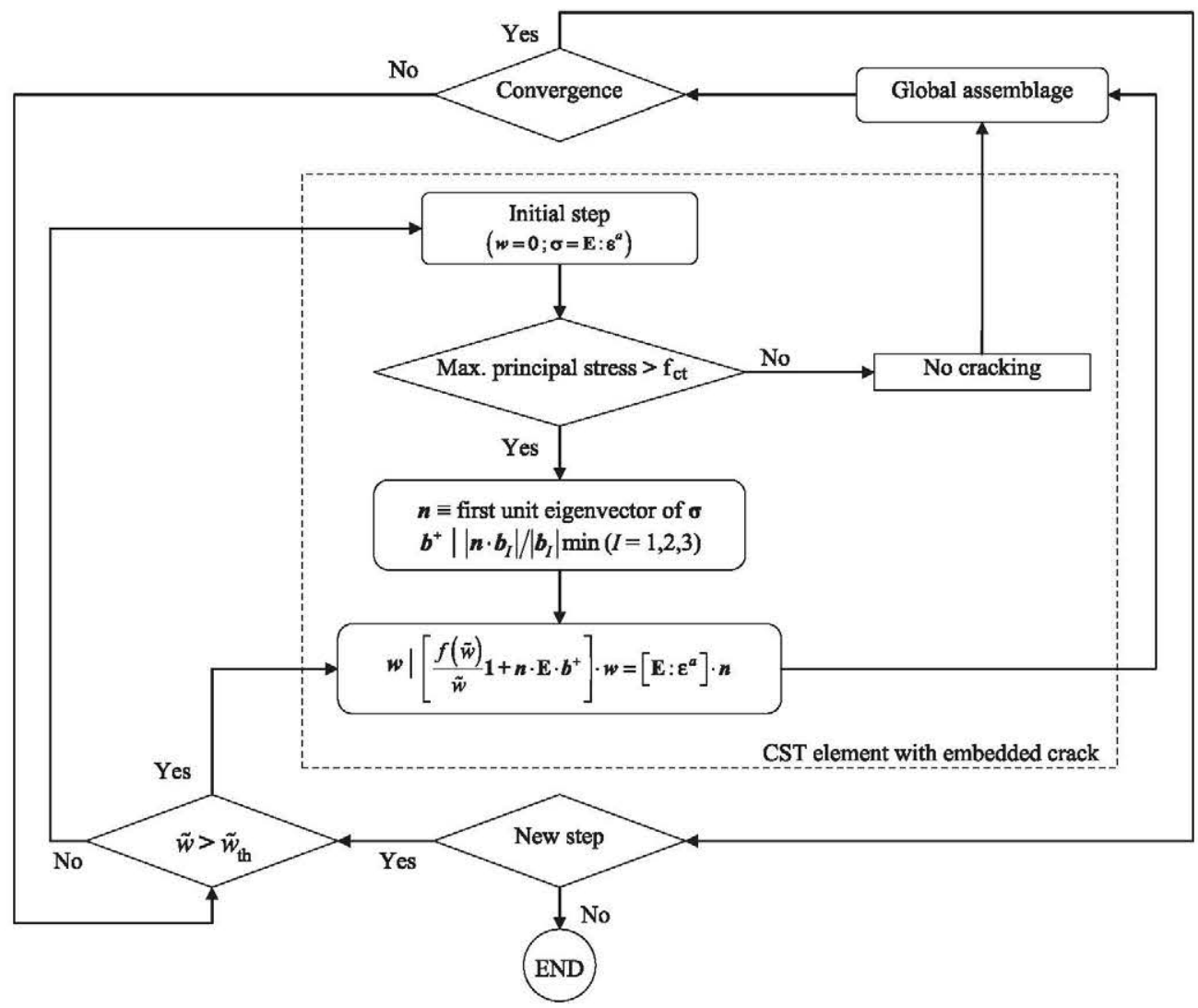

Fig. 5. Schematic flow chart of CST element with cohesive embedded crack. 
where $\mathbf{1}$ is the second order unit tensor.

This equation is solved for $w$ using the Newton-Raphson method given the nodal displacements (and so $\varepsilon^{a}$ ) once the crack is formed and thus $\boldsymbol{n}$ and $b^{+}$are also given.

The process is as follows (see Fig. 5). Within each element, initially, $\boldsymbol{w}=\mathbf{0}$ and linear elastic behaviour is assumed. If maximum principal stress exceeds the tensile strength, then a crack appears perpendicular to the corresponding direction and $\boldsymbol{n}$ is computed as a unit eigenvector of $\boldsymbol{\sigma}=\mathbf{E}: \varepsilon^{a}$. Limiting the analysis to CST elements, a node is selected so that the side opposite to it is as parallel as possible to the crack [22,23,5]. Then, vector $\boldsymbol{b}^{+}$can be determined (see Fig. 3 ).

After solving Eq. (18), to avoid locking after a certain crack growth, the opportunity of crack adaptability within each element is provided, allowing the crack to adapt itself to the later variations in principal stress direction while its opening is small. Threshold value $\tilde{w}_{t h}$ must be related to the softening properties of the material. Values around $0.1-0.2 G_{F} / f_{c t}$, where $G_{F}$ corresponds to specific fracture energy, are usually satisfactory $[22,23]$. Having exceeded these threshold values, crack is considered consolidated and the crack direction becomes fixed.

The Finite Element code FEAP [26] is employed for numerical simulations. Plane strain formulation and exponential softening curve are considered.

\section{Application example}

The numerical model should be contrasted with experimental results (refer to [12]). In the present paper, the reference will be the slab specimen L2 subjected to accelerated corrosion tests developed by Liu [13]. Table 1 summarises main experimental data and Fig. 6 sketches the geometry of the problem.

For the sake of simplicity, the mechanical properties of oxide products are adopted as the steel ones, in accordance with the assumption by Bhargava and Ghosh [2]. The FE model is represented in Fig. 7, with a characteristic element length in the steelconcrete interface of $0.1 \mathrm{~mm}$. As remarked in Section 1, a contact element in the steel (oxide)-concrete interface is necessary to localise cracking and to avoid tensile stress in the reinforcement bar [11]. A perfect sliding contact was chosen here.

Oxide production is modelled as a fictitious increment of temperature in the rebar section, as usually adopted in the literature. The initial radius of steel bar $R_{i}$ is reduced to $R_{i}^{*}$, while corrosion products would reach a radius $R_{i}+\Delta$ if not constrained by concrete (see Fig. 2). As presented before, uniform corrosion around the bar is considered and the plane strain condition is taken into account. In addition, an exponential function for the softening curve with an estimated value of $G_{F}=100 \mathrm{~N} / \mathrm{m}$ is used.

Loss of steel mass $j_{s}$ is related to the annual mean corrosion rate $i_{c o r}$ using Faraday's law:

$$
j_{s}=\frac{M_{F e} i_{c o r}}{n F}
$$

where $M_{F E}$ is the atomic weight of iron $(55.9 \mathrm{~g} / \mathrm{mol}), n$ the valence of the reaction (typically, $n=2$ or 3 ; a value of $n=2.0$ will be assumed here) and $F$ the Faraday constant $(96,500 \mathrm{C} / \mathrm{mol})$.

Table 1

Experimental data of slab specimen L2 [13].

\begin{tabular}{llll}
\hline Parameter & Symbol & Value & Unit \\
\hline Initial rebar diameter & $D_{i}$ & 16 & $\mathrm{~mm}$ \\
Clear cover to the reinforcement & $c$ & 70 & $\mathrm{~mm}$ \\
Rebar spacing & 5 & 1.79 & $\mathrm{~mm}$ \\
Annual mean corrosion rate & $i_{\text {corr }}$ & 31.5 & $\mathrm{~m} / \mathrm{cm}^{2}$ \\
Compressive strength of concrete & $f_{c}$ & 27,000 \\
Modulus of elasticity of cover concrete & $E_{c}$ & 3.3 & $\mathrm{MPa}$ \\
Tensile strength of concrete & $f_{c t}$ & 0.18 \\
Poisson's ratio of concrete & $v_{c}$ & 2.0 & $\mathrm{MPa}$ \\
Creep coefficient for the concrete cover & $\varphi$ & 0.0125 \\
Thickness of porous zone around steel-concrete interface & $d_{o}$ & $\mathrm{~mm}$ \\
\hline
\end{tabular}

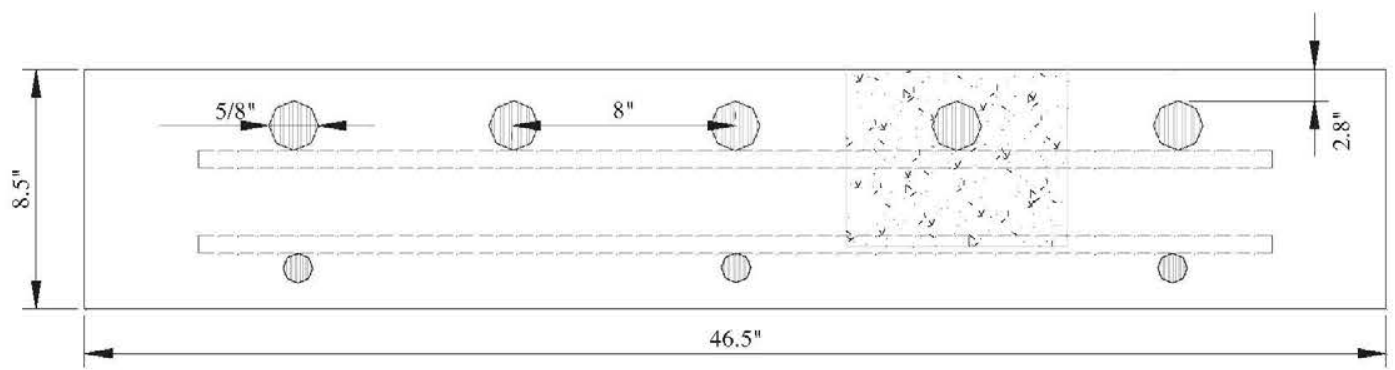

Fig. 6. Sketch of slab specimen L2 [13]. 


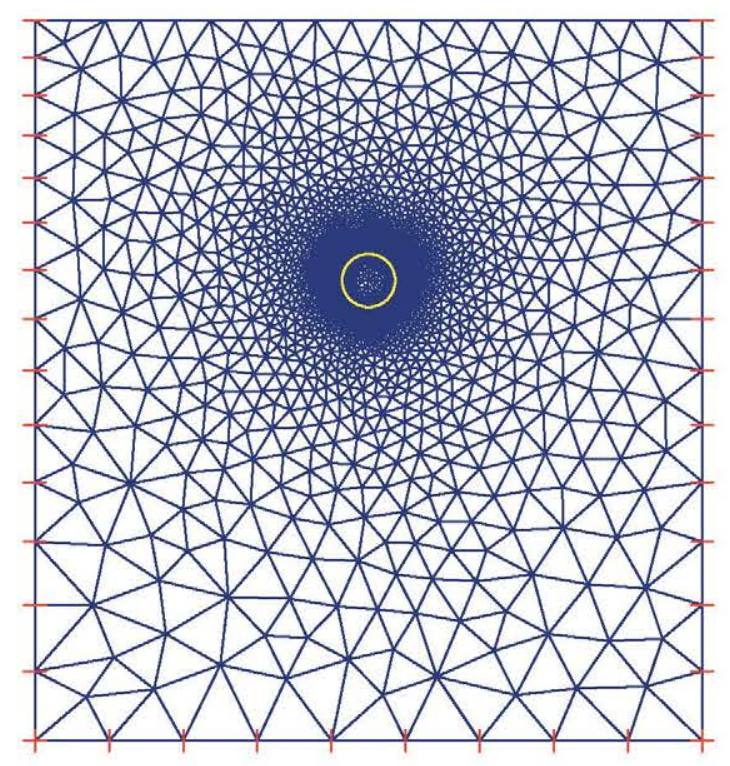

Fig. 7. FE model of slab specimen L2 [13].

On the other hand, the amount of steel per unit length of the reinforcement consumed by the corrosion process $W_{s}$ is given by:

$$
W_{s}=\rho_{s} \frac{\pi}{4}\left(D_{i}^{2}-D_{i}^{* 2}\right)
$$

It is necessary to define the ratio of volume of expansive corrosion products to the volume of steel consumed $\mu_{v}$ :

$$
\mu_{v}=\frac{\left(D_{i}+2 \Delta\right)^{2}-D_{i}^{* 2}}{D_{i}^{2}-D_{i}^{* 2}}
$$

Developing the former expressions, the following emerges, relating $t$ with $\Delta$ :

$$
t(\Delta)=\frac{W_{s}}{\pi D_{i j}}=\frac{\rho_{s}}{4 D_{i} j_{s}\left(\mu_{v}-1\right)}\left[\left(D_{i}+2 \Delta\right)^{2}-D_{i}^{2}\right]
$$

Knowing the ratio of molecular weight of iron to the molecular weight of the corrosion products $\mu_{w}$, the density of rust can be evaluated through the following expression:

$$
\rho_{r}=\frac{\rho_{s}}{\mu_{w} \mu_{v}}
$$

Then, the amount of rust products $W_{r}$ equals $W_{s}$ divided by $\mu_{w}$. The relationship between $\mu_{w}$ and $\mu_{v}$, by Bhargava et al. [4], is used here:

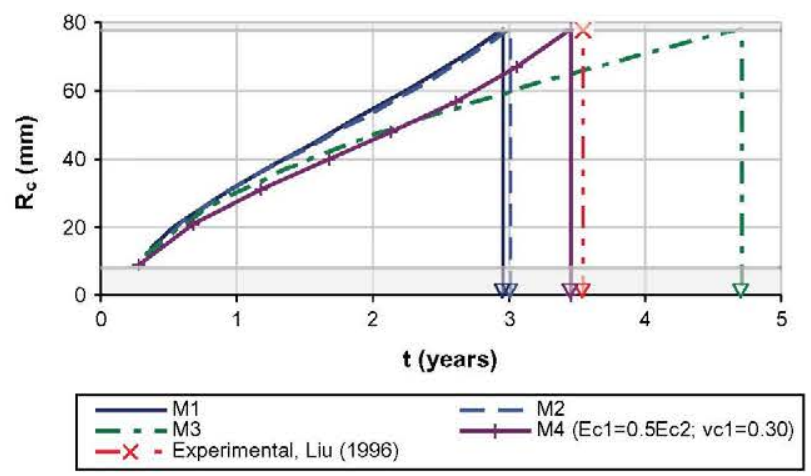

Fig. 8. Time to cover cracking in slab specimen $\mathrm{L} 2$, through different analytical models (experimental data according to Table 1). 


$$
\mu_{v}=10.60138-12.6787 \mu_{w}+1.50424 \mu_{w}^{2}
$$

Considering a density of rust $\rho_{r}=3,600 \mathrm{~kg} / \mathrm{m}^{3}[15]$ and a steel density $\rho_{s}=8,000 \mathrm{~kg} / \mathrm{m}^{3} ; \mu_{w}=0.5596$ and $\mu_{v}=3.9774$ result.

From Eq. (19), if the amount of current $i_{\text {cor }}$ is assumed constant (not always applicable, especially in a highly varying aggressive environment; [6]), the rate of the loss of steel mass $j_{s}$ and, consequently, through $\mu_{w}$ parameter, the rate of rust production are constant. However, some authors (e.g., [15]) consider that the rate of rust production is not unchanging but inversely proportional to the amount of corrosion products, i.e., decreasing with time. These models are based on a timeinvariant parameter $k_{p}$ used to fit experimental data, but differing by more than one order of magnitude among the proposed values in the literature. In this analysis, the rate of rust production is set constant and expressed by means of the Faraday's law; in order not to underestimate the rate of steel loss caused by corrosion [10].

Table 2

Correspondence between times and radial expansion due to rust production, in slab specimen L2 [13].

\begin{tabular}{lllllll}
\hline$\Delta(\%)$ & $D_{i}(\mathrm{~m})$ & $D_{2}(\mathrm{~m})$ & $W_{r}(\mathrm{~kg} / \mathrm{m})$ & $W_{r}\left(d_{o}\right)(\mathrm{kg} / \mathrm{m})$ & $W_{s}+W_{s}\left(d_{0}\right)\left(\mathrm{kg} / \mathrm{m}^{2}\right)$ & $t(\mathrm{year})$ \\
\hline 0.20 & 0.016 & 0.016032 & 0.003871 & 0.003024 & 0.077 & 0.47 \\
0.40 & 0.016 & 0.016064 & 0.007750 & 0.003024 & 0.120 & 0.73 \\
0.60 & 0.016 & 0.016096 & 0.011637 & 0.003024 & 0.163 & 1.00 \\
0.80 & 0.016 & 0.016128 & 0.015532 & 0.003024 & 0.207 & 1.26 \\
\hline
\end{tabular}

(a)

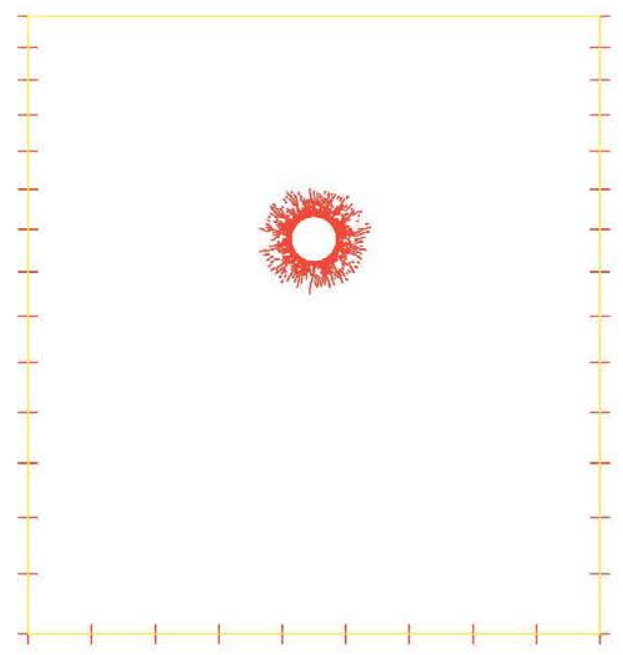

(c)

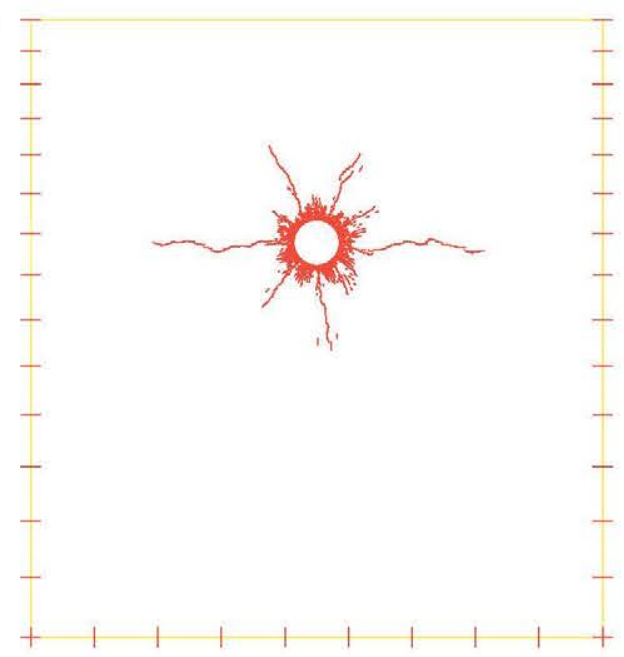

(b)

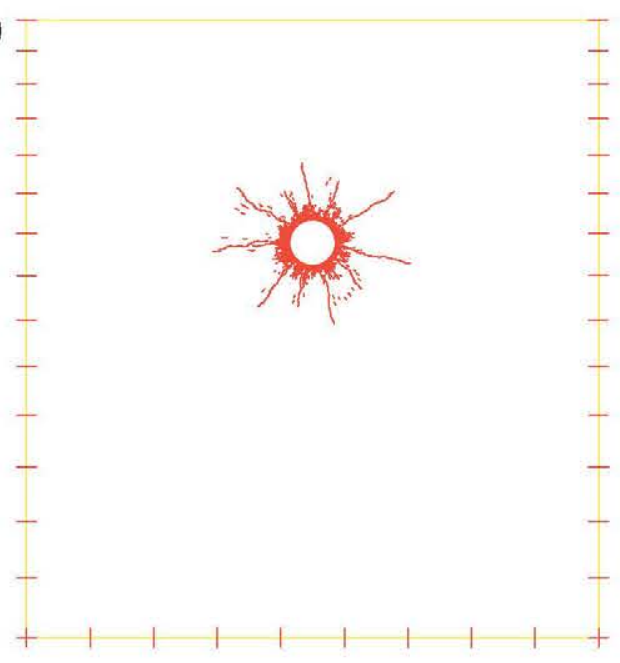

(d)

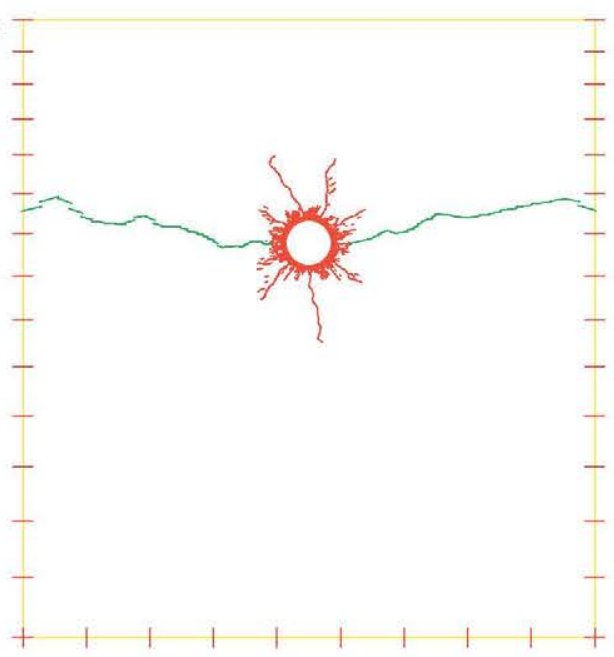

Fig. 9. Crack pattern in slab specimen L2 by FE model (in green, cracks with opening more than $0.1 \mathrm{~mm}$ ): (a) 0.47 years; (b) 0.73 years; (c) 1.00 years; and (d) 1.26 years. 
Additionally, a porous zone (in fact, an especially porous zone, due to voids in the steel-concrete interface) is considered to take into account that corrosion products accumulating around the reinforcement bar do not exert any pressure on the surrounding concrete until they fully fill these voids between steel and concrete. According to Liu and Weyers [15] this porous thickness is equal to $12.5 \mu \mathrm{m}$, which implies an increment in time to cracking of around 75 days, by substituting in the expression:

$$
t\left(\Delta=d_{0}\right) \simeq \frac{\rho_{s} d_{0}}{j_{s}\left(\mu_{v}-1\right)}
$$

As a first approach to the application example, the four analytical models presented in Section 2 are used. Input data are summarised in Table 1 and the main experimental results to reproduce are 3.54 years to cover cracking and $0.579 \mathrm{mg} /$ $\mathrm{mm}^{2}$ for the corresponding amount of steel consumed [13].

In Fig. 8 the experimental time to cover cracking is delimited by the numerical models, from 2.9 to 4.7 years. The corresponding values of $W_{s}$ are between 0.48 and $0.77 \mathrm{mg} / \mathrm{mm}^{2}$, respectively. Then, in spite of their simplicity, the proposed analytical models are able to delimitate the experimental values.

As seen from Fig. 8, the predicted time to cover cracking from Model 3 is the highest one. This is because Model 3, where no residual strength is considered, implies a minimum stiffness. Conversely, both Models 1 and 2 imply a very fast transmission of hoop stresses. Considering a fixed time $t$, Model 2 leads to a value of $R_{c}$ slightly less than that predicted by Model 1 , due to external pressure on reinforcement bar, which hinders its free expansion. Finally, Model 4 appears as an intermediate case. In the figure, elastic parameters defining the cracked concrete behaviour are assumed constant. However, a smooth transition from the first values to the final ones is expected.

Hence, the main conclusions offered by Bhargava et al. [3,4] are corroborated, this time under plane strain assumption and oxide rate production linear with time.

Analytical models suppose a first simple approximation to the problem, through simplifying assumptions such as the central symmetry with respect to the reinforcement bar axis, the use of isotropic materials even under cracking and not taking into account the fill of cracked space by oxide products once the special porous zone around the bar is fully occupied.

The use of a finite element with an embedded cohesive crack model appears as a more consistent method, as indicated before. Table 2 reproduces the relationship between time (years) and radius increment $\Delta(\%)$ and Fig. 9, the corresponding crack pattern for each time.

From Fig. 9a, the corresponding value of $R_{c}$ at very early age as obtained through analytical models is confirmed. A multiple diffuse crack scenario around the reinforcement bar is clearly shown. However, once some localisation of discrete cracks appears, crack patterns are progressively moving away from those expected through axially symmetric analytical models. Estimation of time to surface cracking leads to lower values than experimental ones but, once again, it must be taken into

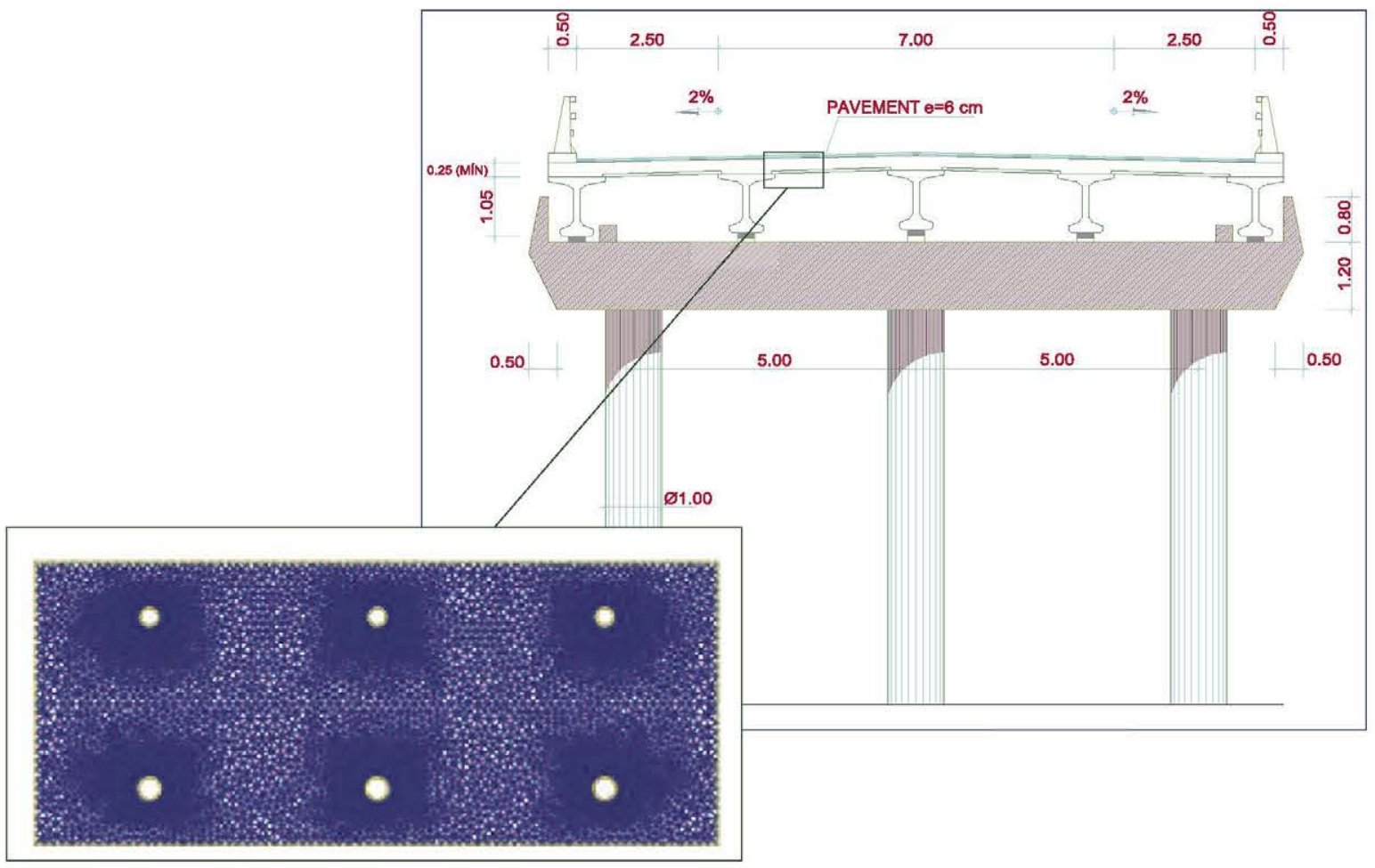

Fig. 10. Extraction of FE mesh from actual bridge geometry. 
Table 3

Parameters used for bridge deck practical case.

\begin{tabular}{llll}
\hline Parameter & Symbol & Value & Unit \\
\hline Initial rebar diameter & $D_{i}$ & 16 & $\mathrm{~mm}$ \\
Clear cover to the reinforcement & $c$ & 40 & $\mathrm{~mm}$ \\
Rebar spacing & $S$ & 200 & $\mathrm{~mm}$ \\
Compressive strength of concrete & $f_{c}$ & 44 & $\mathrm{MPa}$ \\
Modulus of elasticity of cover concrete & $E_{c}$ & 31,700 & $\mathrm{MPa}$ \\
Tensile strength of concrete & $f_{c t}$ & 3.7 & $\mathrm{MPa}$ \\
Poisson's ratio of concrete & $v_{c}$ & 0.2 & 2.0 \\
Creep coefficient for the concrete cover & $\varphi$ & 0.0 & \\
Thickness of porous zone around steel-concrete interface & $d_{o}$ & 110 & $\mathrm{~mm}$ \\
Specific fracture energy & $G_{F}$ & $\mathrm{~N} / \mathrm{m}$ \\
\hline
\end{tabular}

(a)

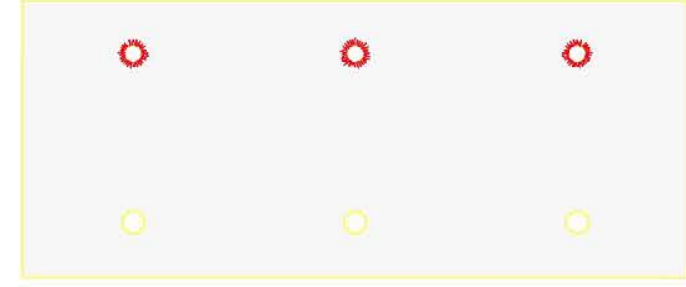

(c)

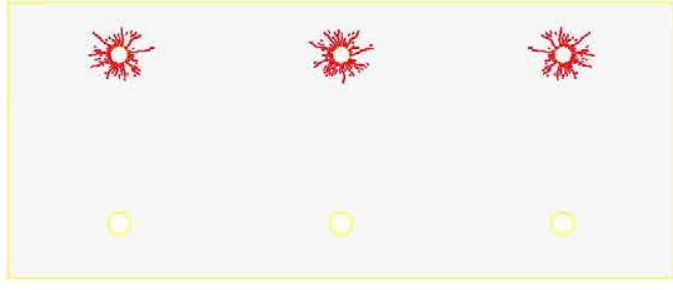

(e)

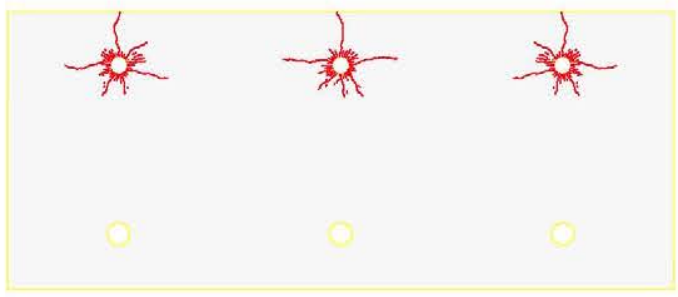

(g)
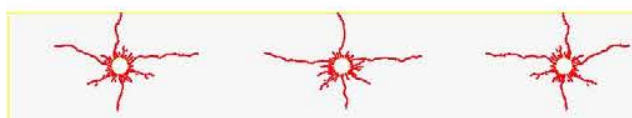

(i)

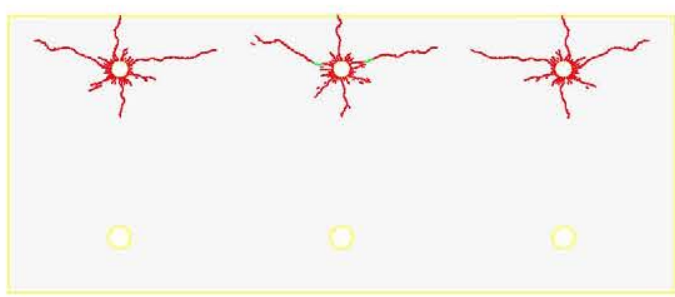

(b)

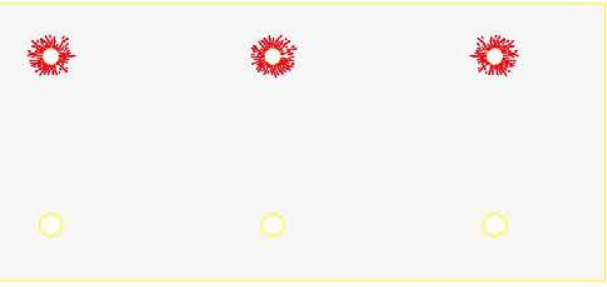

(d)
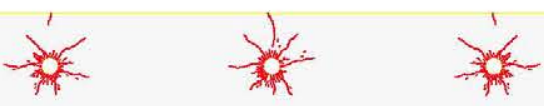

(f)
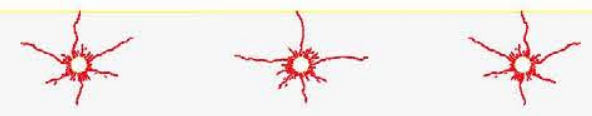

(h)
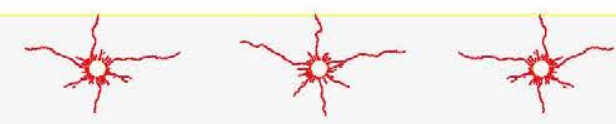

(j)

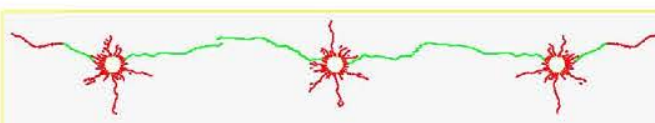

Fig. 11. Upper slabs bridge deck. Cracking patterns due to rebar corrosion: (a) $\Delta=8 \mu \mathrm{m}$; (b) $\Delta=16 \mu \mathrm{m}$; (c) $\Delta=24 \mu \mathrm{m}$; (d) $\Delta=32 \mu \mathrm{m}$; (e) $\Delta=40 \mu \mathrm{m}$; (f) $\Delta=48 \mu \mathrm{m}$; (g) $\Delta=56 \mu \mathrm{m}$; (h) $\Delta=64 \mu \mathrm{m}$; (i) $\Delta=72 \mu \mathrm{m}$; and (j) $\Delta=80 \mu \mathrm{m}$. 
account that no amount of corrosion products has been accommodated within the open cracks during the progress of cracking. In fact, steel losses indicated in Table 2 do not reach by far the experimental value of $0.601 \mathrm{mg} / \mathrm{mm}^{2}$. If we consider the volume of only consolidated cracks in Fig. 9d, approximately $15 \mathrm{~mm}^{2}$ due to maximum crack width around $0.16 \mathrm{~mm}$ (i.e. rust amount of $0.053 \mathrm{~kg} / \mathrm{m}$ ), an additional time to cracking of 3.6 years corresponds. Hence, experimental values can be tallied.

Coming back to crack patterns, as the corrosion process progresses, cracks tend to localise in the horizontal plane between reinforcement bars, in accordance with experimental results. Contrary to other application cases (e.g. [6,12]), early vertical cracks do not appear firstly on the top surface. This is due to the thicker concrete cover considered here. If concrete cover is reduced, a slightly different evolution of crack pattern arises, as shown below.

\section{Upper slab in bridge deck}

As a practical application of the previous model, a bridge deck upper slab exposed to chloride attack is analysed. A 2D finite element mesh is extracted from actual bridge as shown in Fig. 10. The main parameters used in the calculation are indicated in Table 3. However, service life prediction is fully dependent on two basic variables not usually precisely known: the threshold chloride concentration and the corrosion rate. Major conclusions are then referred to the achieved cracking patterns, which matches experimental results in accelerated corrosion tests (e.g. 18). In Fig. 11, cracks with width greater than $0.1 \mathrm{~mm}$ are shown in green. In fact, maximum width around $0.25 \mathrm{~mm}$ is reached in Fig. $11 \mathrm{j}$.

\section{Conclusions}

This paper develops a corrosion-induced cover cracking model based on an embedded cohesive crack finite element. The proposed model is focused on the localisation of discrete cracks and avoids the classical assumption of axi-symmetry around the reinforcement bar. Time to surface cracking and the corresponding amount of steel loss are predicted quite reasonably, according to experimental data and based on Faraday's law. Nevertheless, it is necessary to make some assumptions about the consideration of an especially porous zone around the steel-concrete interface and, particularly, the accommodation of corrosion products within the open cracks generated in the process. Likewise, major limitations refer to the quantitative estimation of corrosion rate and the possible influence of rust mechanical properties around the steel re-bar.

Some simple analytical models, under plane strain formulation, are also presented. It is concluded that, in spite of their limitations and inconsistencies, they are useful for comparative purposes. However, the E-FEM approach provides a more robust solution, capable of being extended to real and practical cases, where complex geometries and effects such as the degree of confinement of the reinforcement bar, are involved. As an example, cracking patterns obtained by the application of the model to actual bridge decks match expectations. It is shown that, as the corrosion process progresses, cracks tend to localise in the horizontal plane between reinforcement bars.

\section{Acknowledgements}

The authors gratefully acknowledge the financial support for the research provided by the Spanish Ministerio de Ciencia e Innovación under grants IPT-42000-2010-31, and DPI2011-24876.

\section{Appendix A}

\section{A.1. Model 1: linear elastic concrete}

Considering $\sigma_{\theta}=f_{c t}$ in $r=R_{c}$, from Eqs. (3) and (4):

$$
f_{c t}=\frac{E_{c}}{1+v_{c}}\left[\frac{A}{2\left(1-2 v_{c}\right)}+\frac{B}{R_{c}^{2}}\right]=\frac{E_{c} B}{1+v_{c}}\left[\frac{1}{R_{0}^{2}}+\frac{1}{R_{c}^{2}}\right]
$$

Similarly, developing $\sigma_{r}=-p_{r}$ in $r=R_{i}+d_{o}$ :

$$
-p_{r}=\frac{E_{c}}{1+v_{c}}\left[\frac{A}{2\left(1-2 v_{c}\right)}-\frac{B}{\left(R_{i}+d_{0}\right)^{2}}\right]=\frac{E_{c} B}{1+v_{c}}\left[\frac{1}{R_{0}^{2}}-\frac{1}{\left(R_{i}+d_{0}\right)^{2}}\right]
$$

Developing the two previous expressions:

$$
\frac{1}{R_{c}^{2}}=\frac{-1}{R_{0}^{2}}-\frac{f_{c t}}{p_{r}}\left[\frac{1}{R_{0}^{2}}-\frac{1}{\left(R_{i}^{+} d_{o}\right)^{2}}\right]
$$

from where Eq. (6) arises immediately. 
A.2. Model 2: linear elastic concrete and steel

Radial stress compatibility between steel and corrosion products and concrete ring is achieved:

$$
-p_{r}=\frac{C E_{s}}{2\left(1+v_{s}\right)\left(1-2 v_{s}\right)}=\frac{E_{c}}{1+v_{c}}\left[\frac{A}{2\left(1-2 v_{c}\right)}-\frac{B}{\left(R_{i}+d_{0}\right)^{2}}\right]
$$

Eq. (3) is used again, to obtain:

$$
\frac{C E_{s}}{2\left(1+v_{s}\right)\left(1-2 v_{s}\right)}=\frac{E_{c}}{1+v_{c}}\left[\frac{1}{R_{0}^{2}}-\frac{1}{\left(R_{i}+d_{0}\right)^{2}}\right] \frac{d_{c} R_{o}^{2}\left(R_{i}+d_{o}\right)}{\left(R_{o}^{2}+\left(1-2 v_{c}\right)\left(R_{i}+d_{o}\right)^{2}\right)}
$$

Unknown factor $C$ is derived from compatibility of displacements:

$$
u_{s}=\frac{C R_{2}}{2}=-R_{2}+R_{i}+d_{0}+d_{c}
$$

As a consequence,

$$
\frac{\left(-R_{2}+R_{i}+d_{0}+d_{c}\right) E_{s}}{\left(1+v_{s}\right)\left(1-2 v_{s}\right) R_{2}}=\frac{E_{c}}{\left(1+v_{c}\right)} \frac{\left(\left(R_{i}+d_{0}\right)^{2}-R_{0}^{2}\right)}{\left(R_{i}+d_{0}\right)} \frac{d_{c}}{\left(R_{o}^{2}+\left(1-2 v_{c}\right)\left(R_{i}+d_{o}\right)^{2}\right)}
$$

From where Eq. (8) results.

\section{A.3. Model 3: cracked concrete with no residual strength and linear elastic steel}

In this model, radial pressure is supposed to be directly transmitted from $R_{c}$ to steel and corrosion products, through cracked concrete. Then,

$$
-p_{r}=\frac{C E_{s}}{2\left(1+v_{s}\right)\left(1-2 v_{s}\right)}=\frac{E_{c}}{1+v_{c}}\left[\frac{A}{2\left(1-2 v_{c}\right)}-\frac{B}{R_{c}^{2}}\right]
$$

The second half of Eq. (3) governs, but now, as stated before, conservation of volume is employed to get a new expression:

$$
u_{c} R_{c}=\left(\frac{A R_{c}}{2}+\frac{B}{R_{c}}\right) R_{c}=\left(\frac{A R_{c}}{2}+\frac{A R_{0}^{2}}{2\left(1-2 v_{c}\right) R_{c}}\right) R_{c}=d_{c}\left(R_{i}+d_{0}\right)
$$

Unknown factor $A$ is given by:

$$
A=\frac{2 d_{c}\left(R_{i}+d_{0}\right)\left(1-2 v_{c}\right)}{R_{0}^{2}+\left(1-2 v_{c}\right) R_{c}^{2}}
$$

Combining (A.8) and (A.10) and making use again of second half of Eq. (3):

$$
\frac{C E_{s}}{2\left(1+v_{s}\right)\left(1-2 v_{s}\right)}=\frac{E_{c}}{2\left(1+v_{c}\right)\left(1-2 v_{c}\right)}\left[1-\frac{R_{0}^{2}}{R_{c}^{2}}\right] \frac{2 d_{c}\left(R_{i}+d_{0}\right)\left(1-2 v_{c}\right)}{R_{0}^{2}+\left(1-2 v_{c}\right) R_{c}^{2}}
$$

Through Eq. (A.6), the former expression is developed as follows:

$$
\frac{\left(-R_{2}+R_{i}+d_{0}+d_{c}\right) E_{s}}{\left(1+v_{s}\right)\left(1-2 v_{s}\right) R_{2}}=\frac{E_{c} d_{c}\left(R_{i}+d_{0}\right)\left(R_{c}^{2}-R_{0}^{2}\right)}{\left(1+v_{c}\right) R_{c}^{2}\left(R_{0}^{2}+\left(1-2 v_{c}\right) R_{c}^{2}\right)}
$$

from where Eq. (9) is directly obtained.

\section{A.4. Model 4: cracked concrete with residual strength and linear elastic steel}

Due to the fact that two different concrete regions are considered, compatibility of both radial displacement and radial stress is enforced at $r=R_{c}$ :

$$
\begin{aligned}
& u_{c}=\frac{A R_{c}}{2}+\frac{B}{R_{c}}=\frac{E R_{c}}{2}+\frac{F}{R_{c}} \\
& \frac{E_{c 2}}{1+v_{c 2}}\left[\frac{A}{2\left(1-2 v_{c 2}\right)}-\frac{B}{R_{c}^{2}}\right]=\frac{E_{c 1}}{1+v_{c 1}}\left[\frac{E}{2\left(1-2 v_{c 1}\right)}-\frac{F}{R_{c}^{2}}\right]
\end{aligned}
$$


Other boundary conditions are given by the displacement $d_{c}$ in $r=R_{i}+d_{o}$ and null radial stress in $r=R_{o}$ :

$$
\begin{aligned}
& d_{c}=\frac{E\left(R_{i}+d_{0}\right)}{2}+\frac{F}{\left(R_{i}+d_{0}\right)} \\
& 0=\frac{E_{c 2}}{1+v_{c 2}}\left[\frac{A}{2\left(1-2 v_{c 2}\right)}-\frac{B}{R_{0}^{2}}\right]
\end{aligned}
$$

Previous expressions allow establishing of the unknown factors $A, B, E$, and $F$ in terms of displacements $u_{c}$ and $d_{c}$ and geometric parameters:

$$
\begin{aligned}
& u_{c}=\frac{A}{2}\left(R_{c}+\frac{R_{0}^{2}}{\left(1-2 v_{c 2}\right) R_{c}}\right) \\
& u_{c}=\frac{u_{c}\left(1-2 v_{c 2}\right) R_{c}^{2}}{R_{0}^{2}+\left(1-2 v_{c 2}\right) R_{c}^{2}}+\frac{B}{R_{c}} \\
& u_{c}=E\left(\frac{R_{c}}{2}-\frac{\left(R_{i}+d_{0}\right)^{2}}{2 R_{c}}\right)+\frac{\left(R_{i}+d_{0}\right) d_{c}}{R_{c}} \\
& u_{c}=\frac{\left(u_{c} R_{c}-\left(R_{i}+d_{0}\right) d_{c}\right) R_{c}}{R_{c}^{2}-\left(R_{i}+d_{0}\right)^{2}}+\frac{F}{R_{c}}
\end{aligned}
$$

Then, through Eq. (A.14):

$$
\frac{E_{c 2}}{1+v_{c 2}}\left[\frac{u_{c} R_{c}}{\left(R_{0}^{2}+\left(1-2 v_{c 2}\right) R_{c}^{2}\right)}-\frac{u_{c} R_{0}^{2}}{\left(R_{0}^{2}+\left(1-2 v_{c 2}\right) R_{c}^{2}\right) R_{c}}\right]=\frac{E_{c 1}}{1+v_{c 1}}\left[\frac{u_{c} R_{c}-\left(R_{i}+d_{0}\right) d_{c}}{\left(1-2 v_{c 1}\right)\left(R_{c}^{2}-\left(R_{i}+d_{0}\right)^{2}\right)}-\frac{\left(R_{i}+d_{0}\right) d_{c} R_{c}-u_{c}\left(R_{i}+d_{0}\right)^{2}}{R_{c}\left(R_{c}^{2}-\left(R_{i}+d_{0}\right)^{2}\right)}\right]
$$

from where Eq. (10) can be derived:

$$
\frac{E_{c 2}\left(1+v_{c 1}\right)}{E_{c 1}\left(1+v_{c 2}\right)}\left[\frac{u_{c} R_{c}^{2}-u_{c} R_{0}^{2}}{\left(R_{0}^{2}+\left(1-2 v_{c 2}\right) R_{c}^{2}\right) R_{c}}\right]=\frac{-2\left(1-v_{c 1}\right)\left(R_{i}+d_{0}\right) d_{c} R_{c}+u_{c}\left(R_{c}^{2}+\left(R_{i}+d_{0}\right)^{2}\left(1-2 v_{c 1}\right)\right)}{\left(R_{c}^{2}-\left(R_{i}+d_{0}\right)^{2}\right)\left(1-2 v_{c 1}\right) R_{c}}
$$

Finally, considering $\sigma_{\theta}=f_{c t}$ in $r=R_{c}$;

$$
f_{c t}=\frac{E_{c 2}}{1+v_{c 2}}\left[\frac{A}{2\left(1-2 v_{c 2}\right)}+\frac{B}{R_{c}^{2}}\right]=\frac{E_{c 2}\left[u_{c} R_{c}^{2}+u_{c} R_{0}^{2}\right]}{\left(1+v_{c 2}\right)\left(R_{0}^{2}+\left(1-2 v_{c 2}\right) R_{c}^{2}\right) R_{c}}
$$

From where Eq. (11) arises immediately.

\section{References}

[1] Andrade C, Alonso C, Molina F]. Cover cracking as a function of bar corrosion: part 1 - experimental test. Mater Struct 1993;26:453-64.

[2] Bhargava K, Ghosh AK. Analytical model of corrosion-induced cracking of concrete considering the stiffness of reinforcement. Struct Eng Mech 2003;16:749-69.

[3] Bhargava K, Ghosh AK, Mori Y, Ramanujam S. Modeling of time to corrosion-induced cover cracking in reinforced concrete structures. Cement Concrete Res 2005;35:2203-18.

[4] Bhargava K, Ghosh AK, Mori Y, Ramanujam S. Analytical model for time to cover cracking in RC structures due to rebar corrosion. Nucl Eng Des 2006;236:1123-39.

[5] Borja RI. A finite element model for strain localization analysis of strongly discontinuous fields based on standard Galerkin approximation. Comput Method Appl M 2000;190:1529-49.

[6] Chen D. Computational framework for durability assessment of reinforced concrete structures under coupled deterioration processes. Ph.D. dissertation, Vanderbilt University, Nashville, Tennessee; 2006.

[7] Chernin L, Val DV, Volkh KY. Analytical modelling of concrete cover cracking caused by corrosion of reinforcement. Mater Struct 2010;43(4):543-56.

[8] Dekoster M, Buyle-Bodin F, Maurel O, Delmas Y. Modelling of the flexural behaviour of RC beams subjected to localised and uniform corrosion. Eng Struct 2003;25:1333-41.

[9] Du YG, Chan AHC, Clark LA. Finite element analysis of the effects of radial expansion of corroded reinforcement. Comput Struct 2006;84:917-29.

[10] El Maaddawy T, Soudki K. A model for prediction of time from corrosion initiation to corrosion cracking. Cement Concrete Comp 2007;29:168-75.

[11] Guzmán S. Modelización del deterioro de tableros de puentes de hormigón por dífusión de cloruros y corrosión de la armadura pasiva. Ph.D. dissertation, Universidad Politécnica de Madrid, Spain; 2010 [in Spanish].

[12] Guzmán S, Gălvez JC, Sancho JM. Cover cracking of reinforced concrete due to rebar corrosion induced by chloride penetration. Cement Concrete Res $2011 ; 41: 893-902$.

[13] Liu Y. Modeling the time-to-corrosion cracking of the cover concrete in chloride contaminated reinforced concrete structures. Ph.D. dissertation, Virginia Polytechnic Institute and State University, Blacksburg, VA; 1996.

[14] Liu Y, Li Y. Mechanistic model and numerical analysis for corrosion damage in reinforced concrete. Int J Fracture 2004;126:71-8.

[15] Liu Y, Weyers R. Modeling the time-to-corrosion cracking in chloride contaminated reinforced concrete structures. ACI Mater J 1998;95(6):675-81.

[16] Molina F], Alonso C, Andrade C. Cover cracking as a function of rebar corrosion: part 2 - numerical model. Mater Struct 1993;26:532-48. 
[17] Morinaga S. Prediction of service lives of reinforced concrete buildings based on rate of corrosion of reinforcement steel. Special Report of Institute of Technology Shimizu Corporation, 23. Japan; 1988

[18] Mullard JA, Stewart MG. Corrosion-Induced cover cracking: new test data and predictive models. ACl Struct ] 2011;108(1)

[19] Oliver X. Modelling strong discontinuities in solid mechanics via strain softening constituve equations. Part 1: fundamentals. Int J Numer Meth Eng $1996 ; 39: 3575-600$

[20] Oliver J, Huespe AE, Sănchez PJ. A comparative study on finite elements for capturing strong discontinuities: E-FEM vs X-FEM. Comput Method Applied Mater 2006;195:4732-52.

[21] Pantazopoulou SJ, Papoulia KD. Modeling cover-cracking due to reinforcement corrosion in RC structures. J Engng Mech 2001;127(4).

[22] Sancho JM, Planas J, Gálvez JC, Reyes E, Cendón DA. An embedded cohesive crack model for finite element analysis of mixed mode fracture of concrete. Fatigue Fract Engng Mater 2006;29:1056-65.

[23] Sancho JM, Planas J, Cendón DA, Reyes E, Gálvez JC. An embedded crack model for finite element analysis of concrete fracture. Engng Frac Mech $2007 ; 74: 75-86$

[24] Sancho JM, Planas J, Fathy AM, Gálvez JC, Cendón DA. Three-dimensional simulation of concrete fracture using embedded crack elements without enforcing crack path continuity. Int J Numer Anal Met 2007;31:173-87.

[25] Simó JC, Oliver X, Armero F. An analysis of strong discontinuities induced by strain-softening in rate-independent inelastic solids. Comput Mech $1993 ; 12: 277-96$

[26] Taylor RL. FEAP - A finite element analysis program. Version 7.5 Programmer Manual; 2005. 